\title{
A Aula em Lomba Grande/Rs (1860-1881) na PersPectiva da Trajetória do Professor Meyer
}

\author{
The Class in Lomba Grande/Rs (1860-1881) The Teacher's Perspective Meyer
}

José Edimar de Souza* profedimar@gmail.com

RESUMO: Objetivo foi reconstruir a partir de memórias arquivadas em documentos aspectos da trajetória do professor Henrique Meyer, soldado Brummer, que a partir de sua dispensa do exército brasileiro se estabeleceu, em 1860, em Lomba Grande - atualmente, um bairro do município de Novo Hamburgo/RS. A pesquisa pretendeu conhecer e compreender como os primórdios do ensino público se constituíram nessa localidade, valendo-se de documentos escolares deste professor. Trata-se de mapas de frequência escolar, apostilas de docência, petições e ofícios localizados em dois fundos arquivísticos - Arquivo do Museu Histórico Visconde de São Leopoldo e Arquivo Histórico do Rio Grande do Sul. A perspectiva teórica orienta-se pela História Cultural que considera as representações construídas em relação ao contexto de análise. A análise documental possibilitou identificar que as práticas nesse lugar agregaram usos e costumes à Cultura Escolar, além de, evidenciar a influência imigrante no processo de escolarização.

PALAVRAS-CHAVE: Trajetória Docente, História da Educação, Imigração Alemã.

ABSTRACT: Objective was to reconstruct from memory stored in documents aspects of the trajectory of Professor Henry Meyer, soldier Brummer that since his discharge from the Brazilian army was established in 1860 in Lomba Grande - currently a neighborhood of Novo Hamburgo/RS. The survey sought to know and understand how the beginnings of public education were formed in this locality, drawing on school documents of this teacher. These are maps of school attendance, teaching handouts, petitions and letters located on two archival collections - Archive Visconde de São Leopoldo and Historical Archive of Rio Grande do Sul History Museum the theoretical perspective is guided by Cultural History considers that representations constructed in relation to the context of analysis. The documentary analysis identified that the practices that place added to the usages and customs Culture School, besides highlighting the immigrant influence in the schooling process.

KEYWORDS: Teaching trajectory, History of Education, German immigration.

\section{Introdução}

Este estudo é um desdobramento da temática que investiga a presença da escola isolada na região do Vale dos Sinos ${ }^{1}$. Em Lomba Grande é considerada um fenômeno híbrido, que se constituiu no decorrer do século XIX com a contribuição de diferentes grupos sociais, bem como, diversas ações que caracterizaram o processo de implantação da escola pública primária nesta região. Nesse sentido, os registros sobre os primeiros tempos de escola neste

\footnotetext{
* Doutor em Educação, com estágio pós-doutoral em Educação. Professor e pesquisador do Programa de PósGraduação em Educação da Universidade de Caxias do Sul - UCS. Vice-líder do Grupo de Pesquisa - História da Educação, Imigração e Memória (GRUPHEIM) e integrante do Grupo de pesquisa - Educação no Brasil: memória, instituições e cultura escolar (EBRAMIC).

${ }^{1}$ Uma primeira versão deste texto foi apresentada no XII Encontro Estadual de História - ANPUH-RS, entre os dias

11 a 14 de agosto de 2014 - São Leopoldo/RS.
}

Hist. R., Goiânia, v. 21, n. 2, p. 158-178, maio/ago. 2016 
lugar, feitos pelo professor Henrique Meyer, contribuem para conhecer e compreender como se desenvolveu o processo de institucionalização da Aula Pública em Lomba Grande.

Lomba Grande que outrora pertenceu ao município de São Leopoldo é, atualmente, um bairro rural do município gaúcho de Novo Hamburgo, situa-se na região metropolitana de Porto Alegre, capital do estado do Rio Grande do Sul. Antes da chegada dos imigrantes alemães, a região de Lomba Grande era conhecida como Feitoria ou Estância Velha, região que interligava a antiga estrada comercial e de tropas, do nordeste do Rio Grande do Sul, descia a serra, na zona de Taquara, seguindo pela planície que se estende entre a margem direita do Rio dos Sinos e os contrafortes da Serra Geral, através das regiões que hoje formam os municípios de Parobé, Sapiranga, Novo Hamburgo e Campo Bom.

A perspectiva teórica sustenta-se na História Cultural, a partir de Burke (2005) e Chartier (2002), considerando as práticas e representações dos sujeitos um modo de caracterizar os fenômenos sociais investigados. Para Stephanou e Bastos (2005), essa corrente teórica representou uma possibilidade de estudos de novos objetos de pesquisa, considerando, por exemplo, o sentido sobre o mundo construído pelos homens do passado e a compreensão dos diferentes processos educativos e escolares. O modo de agir e de referir-se a uma cultura institucionalizada evidencia, nas práticas desempenhadas, um coletivo de atitudes que envolvem os sujeitos e os objetos que constituem uma trajetória elaborada e representam um conjunto de aspectos institucionalizados. Como argumenta Viñao Frago (2008, p. 17) não existe uma cultura escolar, mas sim diversas culturas escolares. Para o mesmo autor, a cultura escolar representa "[...] un conjunto de teorías, [...] principios, normas, pautas, rituales, inercias, hábitos y prácticas [...] sedimentadas a lo largo del tiempo en forma de tradiciones, regularidades y reglas de juego.".

As práticas são criadoras de "usos ou de representações", não são redutíveis à vontade dos problemas de discursos e de normas, encontram-se na construção de uma cultura (CHARTIER, 2002). O modo como os professores desenvolveram e fizeram opção de suas práticas sociais figuraram como "[...] modos de viver, trabalhar, morar [...] Assim, a cultura é sempre tomada como expressão de todas as dimensões da vida, incluindo valores, sentimentos, emoções, hábitos [...]" (OLIVEIRA, 2004, p. 272), destaca-se, no campo de análise, portanto, o aspecto da constituição da docência. 
A análise documental foi desenvolvida a partir de Cellard (2008) e Bacellar (2011), ao considerar a organização e sistematização de quadros e tabelas. Além disso, argumenta Juliá (2001), a discussão sobre os estudos de cultura, em cada período de sua histórica, necessita uma análise a partir de suas relações conflituosas ou pacíficas, bem como ao conjunto das culturas que lhe são contemporâneas.

A história só faz sentido diante do seu contexto; naquele que os sujeitos estão inseridos e/ou pelas diferentes intersecções que os grupos sociais promovem. A História Cultural se constituiu a partir da história francesa dos Annales, apresentando-se como uma abordagem para se pensar a ciência histórica, considerando a cultura como "[...] um conjunto de significados partilhados e construídos pelos homens para explicar o mundo" (PESAVENTO, 2004, p. 15). Nesse sentido, a História é entre outras coisas, um modo de narrar uma parte da história das pessoas e da sua relação com os lugares.

A caracterização do contexto de Lomba Grande considera os diferentes grupos sociais que contribuíram para consolidar o atual território do Estado do Rio Grande do Sul, que ocorreu só no início do século XIX. O nosso Estado foi uma província marcada pelo militarismo, já que as disputas históricas entre portugueses e espanhóis ocasionaram um tardio processo de inserção do território gaúcho ao domínio português. Esse aspecto contribuiu para fortalecer as relações de poder local e regional, favorecendo também a descentralização das decisões administrativas do governo imperial. A quase insignificante ação do estado, no que se refere ao desenvolvimento da escolarização da população gaúcha permitiu que a iniciativa privada ocupasse a lacuna da inexistência de escola, ou seja, aulas públicas.

O pouco investimento do Estado em educação e a opção pela colonização europeia no Rio Grande do Sul, no decorrer do século XIX, contribuíram para constituição de uma identidade específica, de valor étnico, cultural e agrícola nas diferentes comunidades de imigrantes. Nesse sentido, quando falamos da presença da escola, na região do Vale dos Sinos, a representação social mais evidente é a herança cultural germânica.

A Europa deixada pelos imigrantes germânicos em 1824, caracterizava-se pela influência do regime Napoleônico constituído por um conjunto de comunidades marcadas pelas suas particularidades culturais. Ou seja, com a imigração deixavam para trás uma sociedade marcada por uma política repressiva e uma situação econômica precária (SOUZA, 2009). 
Como em muitas comunidades no Brasil, que foram colonizadas pelos alemães, as vilas foram surgindo a partir da abertura de picadas que eram trilhas de acesso a uma propriedade, como aconteceu em diferentes partes da colônia de São Leopoldo. O hábito religioso trazido por estes imigrantes agregava construção de templos: católico ou luterano e que contribuíram para o desenvolvimento de vilarejos, da construção de escolas, de salões de festas comunitárias e de cemitérios. (DREHER, 2008). Nesse sentido, a história da escola neste lugar, está imbricada a história da imigração e colonização do Estado do Rio Grande do Sul.

\section{A imigração alemã, os Brummers e as relações com Lomba Grande}

No século XVIII, com a ocupação europeia nas terras sulinas, a área que compreende a região de Lomba Grande era um rincão pertencente à Fazenda Mascarenhas, de posse de Inácio César Mascarenhas e registrado no distrito do Cahy, na freguesia de Triunfo, sendo o de acordo com o Censo de 1784. (FERNANDES, 2012). A implantação da Real Feitoria do Linho Cânhamo, esta propriedade passou a compor uma fazenda estatal que abastecia as tropas portuguesas que seguiam para os fortes sulinos e a Colônia dos Sacramentos. Com a criação da Aldeia de Nossa Senhora dos Anjos, as terras da Feitoria, ou como argumenta Gertz (2012), Feitoria Velha, passaram a pertencer a este espaço administrativo.

A ocupação desta área de terra pelos diferentes grupos que por ali circularam, como: indígenas, africanos, portugueses e espanhóis se deu pelo princípio jurídico do uti possidetis, com a efetiva ocupação da terra. (FERNANDES, 2012) ${ }^{2}$. Este aspecto favoreceu que alguns posseiros fizessem uso do parcelamento ou arrendamento da terra. E quando os colonizadores germânicos começaram a instalarem-se nesta região, as fragilidades de políticas de ocupação e delimitação de terras comprometeram a relação entre os colonos e indígenas, que nem sempre foi amistosa.

Durante o século XIX, a questão fundiária assume outro caráter para o Estado, e o governo imperial preocupado com o cultivo das terras, lançou para isso mão de um projeto colonizador, criando a Colônia de São Leopoldo, em 1824. De modo geral, os imigrantes

\footnotetext{
${ }^{2}$ Para Fernandes (2012) a legislação de terras que regulamentou a propriedade fundiária em vigor com a Lei de 1850 e seu Regulamento de 1845 produziu um território de fronteira, ou seja, “[...] no lugar denominado Passo da Cruz/Santa Maria, ao lado do banhado do Botiá, na margem esquerda do Rio dos Sinos, hoje Lomba Grande, ocorreu um 'despejo de arrendamento'. (FERNANDES, 2012, p. 40).
} 
vieram em busca de novas possibilidades de vida, que as velhas pátrias europeias, momentaneamente, não poderiam oferecer.

A atividade desenvolvida constituiu-se no cultivo de gêneros para subsistência e a forma usual foi a pequena propriedade, com a instalação na Colônia das primeiras famílias em linhas e picadas. Com os colonos germânicos ocorreu também a prática do artesanato, que levou com o passar dos anos ao surgimento de uma classe média. "Até aí, a estrutura social era latifundiária e escrava, contando também com empregados assalariados". (SOUZA, 2009, p.51).

Para Amado (2002), a legislação brasileira referente à imigração foi extremamente confusa. As disputas territoriais e políticas entre as décadas de 1820 a 1850, bem como as indefinições sobre de quem seriam as responsabilidades do projeto colonizador, deixaram os colonos, por vezes abandonados.

Na década de 1850, os conflitos fronteiriços contra Oribe e Rosas, que envolviam Brasil/Argentina e Uruguai, na região do Rio da Prata, levou o governo Brasileiro a contratar soldados alemães. O deslocamento até o Brasil era por conta do contratante, porém, vantajoso, pois ao término do contrato "[...] cada soldado poderia receber 22.500 braças quadradas de terras coloniais ou viagem de retorno gratuita a qualquer porto Europeu [...]. Outra forma de pagamento seria receber $80 \$ 000$ em ouro." (MARQUES, 2010, p. 187).

Para Tesche (2013), os Brummer constituem outro processo da imigração germânica. Nesse sentido, a partir de 1848, Santana (2010) argumenta que se no primeiro grupo de imigrantes que chegou a partir de 1824 havia famílias de agricultores e camponeses; no segundo grupo, em alguns casos, capitaneado "soldados" 3 por iniciativas particulares havia intelectuais e dissidentes políticos das revoluções de 1848 e 1849.

Os Brummers foram contratados pelo Império para lutar na Guerra contra Rosas, na Argentina, em 1852. Tratavam-se de alemães que haviam participado estreitamente das revoluções liberais sufocadas na Europa a partir de 1848. O Brasil, ameaçado por Rosas em sua fronteira meridional e ocidental elaborou um tratado com o Uruguai e o general Urquiza na

\footnotetext{
${ }^{3}$ Desde a Independência do Brasil, houve a preocupação em constituir um exército particular do Império, temendo os levantes políticos que caracterizaram a primeira metade do século XIX. Tesche (2013) menciona que fazia parte do exército brasileiro uma legião de alemães composta de 1770 homens tanto da infantaria, artilharia e sapadores, todos aliciados em Hamburgo na Alemanha.
} 
defesa de seus interesses. A guerra veio e a derrota de Rosas se deu na batalha em Monte Caseros em 3 de fevereiro de 1852. (TESCHE, 2013).

Dreher (2014) acrescenta que em razão da procedência geográfica dos Brummer é possível afirmar que sua maioria professasse o protestantismo. Um grande número destes "mercenários recrutados" representava formação em nível superior o que favoreceu o rápido engajamento político que tiveram no Brasil.

Com o fim da guerra contra Rosas, em torno de 1.800, alguns deles se estabeleceram no Rio Grande do Sul. Estes, por sua vez, tiveram rápida ascendência sobre os demais imigrantes, pois tinham formação acadêmica, facilidade para aprender outras línguas e participação em diferentes movimentos sociais. Para Kreutz (2000), representaram um "fermento" entre os imigrantes para o desenvolvimento material e cultural. Receberam este apelido Brummer, porque eram questionadores, os que faziam "zunido".

Tesche (2013) acrescenta que estes legionários se caracterizaram em um grupo de homens cuja faixa etária variava entre 17 a 50 anos de idade, de várias instruções e de caráter; alguns inclusive sem conhecimento do serviço militar. Porém, existia entre os soldados veteranos, livres atiradores que ficaram sem meio de vida e com a dissolução do exército ${ }^{4}$ de "Schleswig-Holstein", região norte da Alemanha, não podiam regressar à sua Pátria. Estes acumulavam experiência de revoltas na África, na Índia e outras regiões da Europa. Nesse sentido, "[...] os Legionários provenientes de territórios onde havia inúmeros fatores que indicassem revoluções, guerras, não ficariam aqui no sul, mudos.". (TESCHE, 2013, p. 15).

\section{A Escola da Comunidade Evangélica e a Aula Pública da Lomba Grande}

Os primeiros imigrantes que começaram a chegar em 1824, na Colônia de São Leopoldo, foram instalados no lugar denominado Real Feitoria do Linho Cânhamo e, posteriormente, passaram a ocupar a vasta área que compreendia a antiga Colônia. Thum (2009) argumenta que os imigrantes já tinham o hábito de aprender as primeiras letras e o

\footnotetext{
${ }^{4} \mathrm{Na}$ Alemanha o recrutamento era oficialmente proibido, sendo organizado a partir da Helgolândia britânica (ilha no norte da Alemanha). Com isso a atenção se voltou às cidades hanseática, repletas de emigrantes políticos, onde persistiam maiores agrupamentos do dissolvido exército de Schleswig-Holstein. Estes constituíram uma legião de estrangeiros para o serviço no Brasil, agenciados por Sebastião do Rego Barros. A situação destes soldados, muitos irrequietos pela situação de ao retornarem não poder ocupar os cargos militares que ocupavam em 1848, frustrados, aguardando nova oportunidade, candidatar-se como mercenário para o exército brasileiro representava novas expectativas. (TESCHE, 2013).
} 
processo de contar. Isto fez com que as próprias comunidades criassem suas escolas. Esse hábito vem dos processos da Reforma e da Contra-reforma, marcados pelo fato de que Martinho Lutero muito se empenhou para a popularização da leitura da Bíblia.

Kerber, Schemes e Prodanov (2012) acrescentam que entre as comunidades de imigrantes alemães, tanto evangélicas quanto católicas, estabeleceram-se escolas comunitárias em língua alemã, desde meados do século XIX até o começo do século XX. Esse aspecto favoreceu uma tradição escolar e que de acordo com Grützmann, Dreher e Feldens (2008), fez do Estado o mais alfabetizado da Federação e, por muito tempo, significativo polo da produção de material didático, de imprensa e de literatura em língua alemã.

Os imigrantes estavam habituados à existência de um sistema escolar bastante satisfatório em sua terra de origem. Como o governo Imperial não implantou escolas nas regiões de imigração dos alemães, os próprios colonos se organizaram, criando e sustentando as suas escolas. (KREUTZ, 1994). As escolas étnicas dos imigrantes, no Brasil, foram um espaço de afirmação e de reelaboração das características culturais dos diversos grupos que as organizaram, sendo, nos núcleos rurais, chamadas "Gemeindeschule", escolas comunitárias. (KREUTZ 2005).

A falta de escolas públicas levou as comunidades a esta organização independente, que, inclusive, foi assunto de discussão do Presidente da Província e da Assembleia Legislativa da Província de São Pedro do Rio Grande do Sul na década de 1850. As assim denominadas Gemeindeschulen caracterizavam-se pela unidocência e pela predominância do uso da língua alemã como língua básica para o processo de ensino-aprendizagem e comunicação em sala de aula.

Para Dreher (1993), com a Escola-Igreja ou Capela-Escola ${ }^{5}$, surge também um espírito de "comunitarismo" que fortalece a prática das escolas comunitárias, ou seja, reforçava-se o pronome "nossa" cuja prática social fazia com que cada comunidade se constituísse em micro representação da Igreja isolada e autônoma. Como argumenta Rambo (2002), esse aspecto se preservou em muitas regiões rurais até os anos 1860, momento que Kreutz (2002) caracteriza

\footnotetext{
${ }^{5}$ Em Campo Bom a Escola Evangélica- Luterana foi seguramente a primeira escola evangélica instituída no Rio Grande do Sul, conforme Dreher (1992). E tendo o pastor Klingelhoeffer como primeiro professor. (AUTOR, 2009). Além disso, Fleck (2001) recupera as diferentes nomenclaturas da instituição desde a "Geimeindeschule" até o Colégio Sinodal Tiradentes. Autor (2013) acrescenta que são 185 anos de história edificada na história da educação da comunidade campo-bonenses.
} 
como de maior atenção do Estado e da Igreja no processo de implantação da escola pública popular.

A Capela-Escola, como sinaliza Kreutz (1994), foi uma das primeiras experiências comunitárias de escola dos imigrantes europeus. Nas primeiras Escolas-Capela, que geralmente eram casas muito rudimentares, cantava-se, rezava-se e se lia palavras da Bíblia. (DREHER, 1993). No que se refere ao currículo desta escola, que Rambo (1994) identifica como "escola de improviso", a instrução era dada em alemão, pelo menos parcialmente, porque poucos eram os professores que, como recém-imigrados, entendiam o português.

A escola da Comunidade Evangélica-Luterana ${ }^{6}$ de Lomba Grande - Gemeindeschule, foi oficialmente fundada em 08 de fevereiro de 1842 e sabe-se que funcionava desde 1834 em um antigo prédio que servia às pregações dos "cura de almas" e onde também acontecia alfabetização dos filhos dos colonos ${ }^{7}$. (MÜLLER, 1984).

Um aspecto importante a se considerar é que, dentre os colonos que se radicaram na Colônia de São Leopoldo, ou seja, na região atual do Vale dos Sinos, havia imigrantes com formação superior como é o caso do pastor Klingelhöeffer, o que contribuiu para que as escolas fossem instaladas, antes mesmo que os templos religiosos. (SOUZA, 2011). Em Lomba Grande, o primeiro professor da Gemeindeschule foi João Michel Paul Gaspar ${ }^{8}$ que deve ter trabalhado como professor até 1842 e que fora substituído por João Guilherme Gäelzer ${ }^{9}$.

Entre 1846 a 1860, o professor deve ter sido Gäelzer e, entre 1860 a 1881, o professor Henrique Meyer, que não mediu esforços para que um prédio escolar fosse construído, como se observa na fotografia 01 abaixo,

\footnotetext{
${ }^{6}$ A expressão "evangélico-luterano" refere-se ao termo "evangélico", utilizado pelas próprias lideranças e comunidades em publicações da época e na tradição oral. Dreher (2002) argumenta que, com o advento do Pentecostalismo, este conceito vem sendo aplicado sempre mais a esse grupo. Rambo (2002) acrescenta que foi a Igreja Protestante Alemã, aquela trazida pelos imigrantes, em 1824, e que mais tarde se tornaria conhecida com o nome de Igreja Evangélica de Confissão Luterana. Mas, a partir de 1900, implantou-se também a Igreja Luterana do Brasil, vinculada ao Sínodo de Missouri.

${ }^{7}$ A Capela-Escola, até 1834, foi em estilo "pau a pique", ou Lehmkirche - escola de barro-. (MÜLLER, 1984).

8 Johann Michel Paul Gaspar. Faleceu em 1847, com 65 anos. (MÜLLER, 1984).

9 Johann Wilhelm Gäelzer. A família Gäelzer imigrou para o Brasil em 1852, fixando-se inicialmente em Lomba Grande, onde Guilherme Gäelzer - pai do mucker Henrique Guilherme - era professor da comunidade evangélica. Depois se mudou para o Morro Pelado e lá transportava produção agrícola, tornou-se transportador abastado e seu filho foi trabalhar com ele. Henrique Guilherme Gaelzer, 24 anos, preso, três vezes por causa das atividades Mucker, casado com Maria Sehn, segundo o rito de Jacobina. Guilherme Gäelzer Neto foi criado pelo pai, Henrique Guilherme Gäelzer, pois a mãe, Maria Sehn, fora morta no combate de 19 de julho de 1874. (AMADO, 2002, p. 238).
} 
Fotografia 01 - Casa Pastoral - Lomba Grande (1921).

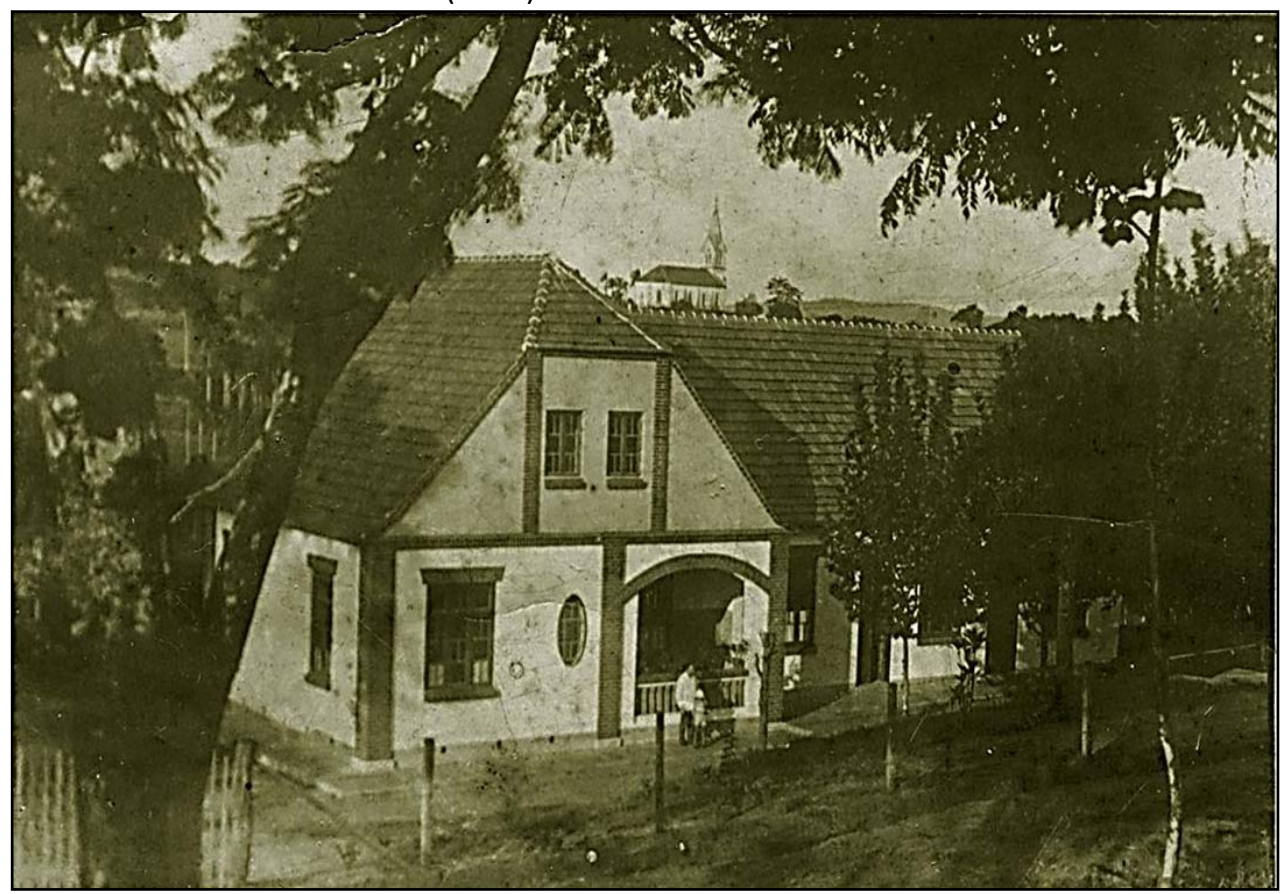

Fonte: Acervo particular do autor.

O professor Henrique Meyer, Brummer, propôs uma campanha entre os paroquianos para construção de uma Escola. Com a construção do prédio escolar, este também serviu de moradia para o professor e abrigou a primeira Aula Pública da Lomba Grande. Em relação à primeira Aula Pública do lugar, em 1859, a Aula da Comunidade Evangélica, do professor Meyer, abrigou a primeira Aula Pública. Meyer ocupou a cadeira do sexo masculino enquanto a cadeira pública do sexo feminino só foi provida na localidade na década de 1880.

O prédio escolar, que também serviu de Casa Pastoral, deve ter sido inaugurado entre 1862 a 1864, como consta nos registros do Arquivo da Secretaria de Desenvolvimento Urbano de Novo Hamburgo. Em 1890, foram construídos dois quartos e, a partir de 1915, foi moradia dos pastores da Igreja Evangélica-Luterana. A última reforma total na arquitetura do prédio foi feita pelo pastor Jacob Sauer, em 1928, dando ao conjunto a aparência atual. A partir de 1915, as Aulas da Escola da Comunidade de Lomba Grande passaram por uma reorganização e, até 1939, não seguem um padrão de referência, conforme identificados em diferentes documentos consultados ${ }^{10}$.

\footnotetext{
${ }^{10}$ Esse aspecto se relaciona com o fato de em determinados anos a escola ter recebido subvenção escolar do governo municipal e/ou estadual. Destaca-se que entre 1915 a 1939 os pastores também eram os professores da escola. (SÃO LEOPOLDO, [1927?]). Essa escola apresenta um caráter híbrido na história da sua trajetória, dentre os nomes que estão associados a ela, além do Gemeindeschule, ou escola da comunidade Evangélica -
} 


\section{Notas sobre a trajetória docente de Henrique Meyer}

No século XIX, acreditava-se que através da instrução pública seria possível arregimentar o povo para um projeto de país independente, criando também as condições para uma participação controlada na definição dos destinos do país. Em função da descentralização proposta pelo Ato Adicional de 1834, o argumento da instituição escolar adquiriu sentidos diversos em cada província do Império brasileiro e a instrução primária, posteriormente foi substituída pela expressão: instrução elementar. (FARIA FILHO, 2010).

A partir de 1850, o discurso a favor da difusão da escola primária como função do Estado foi tomando força e ganhando adeptos dentro e fora do parlamento brasileiro, em projetos de reforma, decretos, regulamentos, relatórios, discursos e escritos diversos. 0 Regulamento decorrente da Reforma Couto Ferraz (1854), no qual constava um artigo sobre a obrigatoriedade de ensino, já se podia vislumbrar a ideia de sistema começando a ser delineada. Embora o Regulamento vigorasse apenas na capital do Império, o mesmo deveria servir de modelo às demais províncias. (SCHELBAUER, 2009).

O sentido que a importância da escolarização adquiriu a partir dos anos 1860, no Brasil, representou o resultado dos debates e do aparecimento de uma ainda frágil tradição de busca de estabelecimento de um mínimo de organicidade e articulação entre os poderes instituídos e cuja "educação primária" estivesse ordenada de acordo com preceitos estabelecidos por leis gerais. (FARIA FILHO, 2010). Além disso, observa-se que o debate da educação pública caracterizava-se pela necessidade do Estado nacional garantir a construção da nacionalidade, ideário que circulava na Europa, desde a difusão do pensamento iluminista.

Amado (2002) argumenta que em 1857, percebe-se uma ação mais direta do governo brasileiro, sobre a rede educacional de São Leopoldo. Havia três escolas públicas existentes e representavam $10 \%$ do total da rede escolar do município. Desde o início da década de 1860, o governo passou a se preocupar com o fato de os colonos não conhecerem o português e se manterem afastados dos principais aspectos da vida brasileira. Em 1870 as dezessete escolas do governo já eram 39,5\% do total. (ALMANACK, 1934). Mas a maioria dos colonos, entretanto, continuou a mandar seus filhos para as

Luterana de Lomba Grande, encontrei as seguintes identidades: Escola Protestante; Escola dos Alemães; Aula da Comunidade Evangélica; Aula Particular da Comunidade Evangélica e Aulas Subvencionadas da Comunidade Evangélica de Lomba Grande. (SÃO LEOPOLDO, 1934). 
escolas alemãs. Em alguns casos os alunos frequentavam as duas escolas paralelamente, como se constata no mapa de frequência da professora de Hamburgo Velho, Professora Brinulfa do Carmo Leopoldina de Castro, em 1861.

Aprender a ler, escrever, calcular e os preceitos religiosos foram aspectos culturais que os imigrantes trouxeram consigo na bagagem, bem como adquiriram um modo próprio e singular diante do contato com as coisas do novo lugar que escolheram para sua morada. Isso contribuiu para que, no início do período republicano, São Leopoldo, em relação ao resto da Província, apresentasse altos índices de escolaridade. (AMADO, 2002). Desde o princípio, a comunidade reconhecia importância e atribuía valor a alguém do grupo social para que este dedicasse uma parte do seu tempo para ensinar as crianças do lugar.

Em relação à primeira Aula Pública do lugar, Meyer foi professor durante muitos anos. Nomeado em 12 de novembro de 1859 entrou em exercício apenas em 3 de dezembro de 1859, como consta no documento transcrito:

[...] O professor da cadeira da Lomba Grande, no municipio de S. Leopoldo, Henrique Meyer, de que trata este Título, achando-se compreendido no art. 45 da lei n. 1158 de 23 de Maio de 1878, tem direito aos vencimentos de professor normalista a contar de 4 de Dezembro de 1879, dia posterior ao em que completou vinte anos de effectivo serviço no magisterio. [...] Porto Alegre, 22 de Abril de 1880. [...]. (APOSTILLA) ${ }^{11}$.

Ainda sobre a instalação desta Aula Pública, há um conjunto de quatro páginas manuscritas, frente e verso, localizados no Arquivo Histórico do Rio Grande do Sul, assim registra:

Aos oito dias do mês de novembro de mil oitocentos e cincoenta e nove [...] no Paço da Camara Municipal desta Villa de São Leopoldo, reunidos os membros abaixo afsignados, comparecerão Felippe Dexheimer, Henrique Breger, Felippe Brohrer, e Federico Guilherme Mufs, e declararão, que em conseqüência de serem oferecido ao Excellentifsimo Senhor Presidente da Provincia uma casa prompta para nella funcionar a Aula Publica do primeiro Gráo de Instrucção primaria do sexo masculino novamente creada no lugar denominado Lomba Grande - na Feitoria Velha, primeiro Districto desta Villa [...] e se obrigão aconservar a dita Casa ou outra qual quer propria para a referida Aula, à sua custa enquanto existir ali a mencionada Aula [...]. (SÃO LEOPOLDO, 1859, fls. 69a).

Meyer foi um professor que se destacou como educador da região no século XIX. Ele integrou bancas examinadoras de concursos para o magistério público gaúcho no final do

\footnotetext{
${ }^{11}$ Tratando-se de uma investigação histórica, optou-se em preservar a forma de escrita original do documento.
} 
século XIX e, seu filho, Emilio Meyer, também professor, atuou na Escola Normal de Porto Alegre, no século XX, nas cadeiras do curso preparatório.

Há um conjunto de documentos significativos sobre o período de trabalho do professor Henrique Meyer, ele apresenta diferentes quadros, que evidenciam o número de alunos que concluíram o ensino primário em Lomba Grande. Entre 1860 a 1876, ele teria formado 263 crianças do sexo masculino e entre 1860 a 1870, teria formado 134 do sexo feminino ${ }^{12}$. A média anual de alunos "dados prontos" versava entre nove a vinte e dois alunos, as idades entre oito a catorze anos.

A transcrição dos documentos localizados no Arquivo do Museu Histórico Visconde de São Leopoldo permite identificar o sobrenome de algumas das famílias das primeiras levas de imigrantes que se radicaram em Lomba Grande, como se observa na tabela 01 abaixo:

Tabela 01- Relação De Alunos Da Aula Pública De Lomba Grande Em 1861

\begin{tabular}{l|l}
\hline \multicolumn{1}{l}{ Nomes de alunos } & 29 Frederico Dickel \\
\hline 1 Carlos Koll & 30 Jacob Hiller \\
\hline 2 Gustavo May & 31 Henrique Eltz \\
\hline 4 Philippe Bohrer & 32 Carlos Weber \\
\hline 5 Pedro Matte & 33 José Pedro Schmitt \\
\hline 6 Theophilo Matte & 34 João Kumpf \\
\hline 7 Lourenço Dexheimer & 35 Ovidio Alves d'Albuquerque \\
\hline 8 Pedro Born & 36 Henrique Blum \\
\hline 9 Frederico Born & 37 Jorge Jung \\
\hline 10 Jacob Roos & 38 Frederico Jung \\
\hline 11 João Sulzbook & 39 João Lindnmeyer \\
\hline 12 Christiano Matte & 40 Christiano Schweitzer \\
\hline
\end{tabular}

\footnotetext{
12 Há um conjunto de documentos que fora encaminhado pelo professor Meyer em 1881 a Diretoria Geral da Instrução Pública, peticionando que durante dez anos ele cumpriu dupla jornada de trabalho ministrando também aula para as meninas da localidade, e que foi indeferido pelo governo estadual.Como consta neste fragmento: “Diz Henrique Meyer, professor publico efetivo da Lomba Grande [...] que tem feito tudo quanto é possível e está em suas forças para dignamente cumprir com a sagrada obrigação de seu magisterio, dedicando-se assim por 21 annos, e, sem interrupção mais do que 3 dias que gozou de licença. Todo esse esforço [...] provada [...] pelos inspectores da parochia, que lhe facilitaram os inclusos atestados sob numos. 1 a 6, que os junta como documentos, demonstrando quanto interesse tomou o peticionário na instruç̧ão dos brasileiros filhos dos colonos alemães, interesse e dedicação taes que obrigaram o peticionário a recorrer 0 ensino de um outro idioma, isto é, o alemão e o brasileiro para o fim de poder ser bem comprehendido, e disso tirarem resultado os seus alumnos e alumnas, como com effeito sucedeu, e isto também está provado com os mapas anexos desde o anno de 1860 até o corrente de 1880, dando em todos os anos mais de 10 alumnos prontos; vindo assim dar durante esse tempo 316 alumnos promptos. Ainda acresce, que o peticionário desde o anno de 1859 até 1870 tambem leccionou em cada anno de $\mathbf{5 0}$ a $\mathbf{7 0}$ meninas sem nenhuma retribuição, sendo por isso e durante mais de 10 annos considerada sua aula como mixta; e assim tão sobrecarregado, não teve antes nem depois um ajudante ou adjunto para o ajudar no pesado ensino de que se via abarbado, e ainda menos teve uma qualquer gratificação. [...].". (MEYER, 1881, fls. 1 e 2 grifo nosso).
} 


\begin{tabular}{l|l}
\hline 13 João Wink & 41 Carlos Schweitzer \\
\hline 14 Jacob Röhrer & 42 Frederico Konrath \\
\hline 15 Ernesto Cajsec & 43 Manoel Pedro da Silva \\
\hline 17 Francisco Lied & 44 Domingos José de Mello \\
\hline 18 Carlos Dioesoher & 45 João José de Mello \\
\hline 19 Carlos Knewitz & 46 João Beck \\
\hline 20 André Sulzbook & 47 Jacob Knewitz \\
\hline 21 Bernardo Winter & 48 Christiano Roos \\
\hline 23 Miguel Danher & 49 Henrique Lied \\
\hline 24 Carlos Kurjober & 50 Nicoláo Röhrer \\
\hline 25 Hadriano José de Oliveira & 51 Pedro Diehl \\
\hline 26 Bibiano Ferreira Nunes & 52 Philippe Roth \\
\hline 27 João da Silva Sprenger & 53 Christiano Kufeler \\
\hline 28 Lourenço Becker & 54 Christiano Lindenmeyer \\
\hline
\end{tabular}

Fonte: Elaborada pelo autor (2014).

Os sobrenomes demonstram que a escola que outrora foi iniciada pelos imigrantes, na década de 1860 acolhia também alunos dos outros grupos étnicos que já haviam se estabelecido na região, como exemplo a família Oliveira, Nunes, Silva e Mello ${ }^{13}$. Além disso, os sobrenomes representam também as famílias tradicionais deste lugar, como os Bohrer, Becker, Winter, Wicker. Sprenger, Konrath, cuja influência escolar foi imprescindível para que as futuras gerações ocupassem cargos burocráticos e até mesmo de cunho político na cidade de São Leopoldo.

Meyer informa ainda que entre 1860 a 1876 teria sido examinado 263 alunos do sexo masculino e 134 alunas do sexo feminino, como se observa na Tabela 02. Nesse sentido, é preciso considerar que os alunos costumavam frequentar a escola entre três a cinco anos, o que implica reconhecer que a presença da escola neste lugar precede a 1860.

Tabela 02 - relação de alunos que foram aprovados nos exames finais do curso primário

\begin{tabular}{l|l|l|l}
\hline \multicolumn{2}{l|}{ Sexo masculino } & \multicolumn{2}{l}{ Sexo feminino } \\
\hline Ano & No de alunos prontos & Ano & № de alunos prontos \\
\hline 1860 & 14 & 1860 & 10 \\
\hline 1861 & 11 & 1861 & 12 \\
\hline 1862 & 17 & 1862 & 7 \\
\hline 1863 & 14 & 1863 & 11 \\
\hline 1864 & 14 & 1864 & 7 \\
\hline 1865 & 10 & 1865 & 13 \\
\hline 1866 & 16 & 1866 & 12 \\
\hline 1867 & 13 & 1867 & 19 \\
\hline
\end{tabular}

\footnotetext{
13 Sobre os descendentes lusos na região, um estudo de cunho genealógico, realizado por um morador de
} Lomba Grande é o trabalho de Dinóra Gomes (2000). 


\begin{tabular}{|c|c|c|c|}
\hline 1868 & 9 & 1868 & 17 \\
\hline 1869 & 16 & 1869 & 15 \\
\hline 1870 & 11 & 1870 & 11 \\
\hline 1871 & 20 & \multicolumn{2}{|c|}{ Total 134 alunas prontas } \\
\hline 1872 & 22 & \multirow{6}{*}{\multicolumn{2}{|c|}{$\begin{array}{l}\text { Em } 1870 \text { abriu-se neste lugar uma aula } \\
\text { particular e subvencionada para as } \\
\text { meninas, a qual em } 1875 \text { passou a ser } \\
\text { Aula Pública do sexo feminino da Lomba } \\
\text { Grande. }\end{array}$}} \\
\hline 1873 & 18 & & \\
\hline 1874 & 15 & & \\
\hline 1875 & 14 & & \\
\hline 1876 & 29 & & \\
\hline \multicolumn{2}{|c|}{ Total 263 alunos } & & \\
\hline
\end{tabular}

Fonte: Meyer (1880b).

Outro documento, disponível em Souza (2015), informa a relação dos alunos que concluíram o ensino primário nos últimos cinco anos de docência do professor Meyer, formando 82 alunos, entre 1876 a 1880. Destaco deste outro documento que refiro um conjunto de sobrenomes das famílias da localidade: Deckmann, Roos, Becker, Scherer, Faller, Dauber, Bohrer, Strack, Diehl, Dexheimer, Homem. Conforme referido anteriormente, são sobrenomes recorrentes em outros documentos acessados na pesquisa desenvolvida em outro estudo. Um detalhe interessante é pensar que mesmo a aula sendo pública, o maior interesse em encaminhar os filhos para a escola permanecia sendo das famílias de descendência germânica.

Em relação aos mapas de frequência e acompanhamento de alunos, como se observa na figura 01 abaixo, alguns detalhes são elucidativos para compreender o cotidiano das práticas pedagógicas dos professores públicos no final do século XIX. 
Figura 01- Mapa trimestral de alunos - Aula Pública da Lomba Grande - 1862.

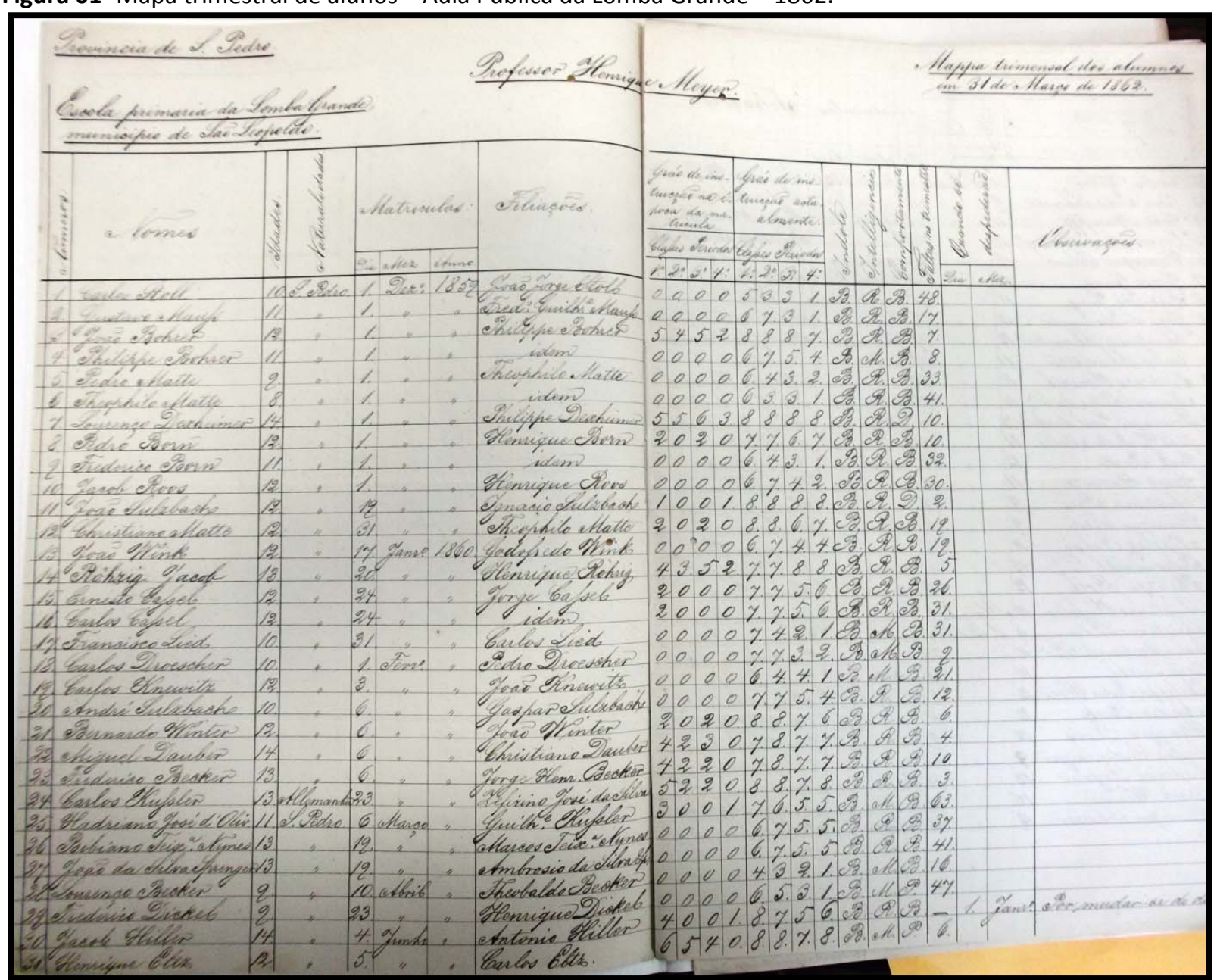

Fonte: Acervo particular do autor (2014).

Os mapas eram encaminhados à Diretoria da Instrução Pública na capital da Província em duas situações. Havia um envio mensal da frequência e um envio trimestral que incluía informações pedagógicas e sobre o desenvolvimento dos alunos. Como se observa na figura 01, a lista de alunos estava organizada pela data de inscrição e não respeitava uma ordem alfabética. Junto com o nome dos alunos, filiação (nome do pai apenas), idade, data de matrícula e a informação da naturalidade permite compreender que logo que chegavam à Província os imigrantes instalados em Lomba Grande matriculavam os filhos na escola antes de seguir para o interior da Colônia. Este é o caso de Carlos Kuzsler e de Jacob Hiller.

Diferente do mapa de frequência que consistia em uma lista com nome de alunos e a mensal, suas presenças no mapa trimestral eram incluídas as informações referentes ao grau de instrução de cada aluno "no momento da matrícula e a situação atual". Havia quatro classes e cada classe poderia ser organizada em diferentes períodos de adiantamento. 
Schneider (1993) argumenta que na década de 1860 o ensino primário no Rio Grande do Sul se constituía das seguintes classes/períodos, como se identifica na Tabela 03 abaixo:

Tabela 03- Classes e períodos do ensino primário (1862)

\begin{tabular}{|c|c|}
\hline Classes & Período \\
\hline 1. .Leitura; Noções de Gramática e Escrita & $\begin{array}{l}\text { 10 conhecimento das letras } \\
\text { 2o sílabas } \\
\text { 3ㅇ soletrar } \\
\text { 4ㅇ leitura corrente } \\
\text { 5ㅇ noções gramaticais }\end{array}$ \\
\hline 2a. Ortografia Prática & $\begin{array}{l}\text { 10 linhas e letras } \\
\text { 2ㅇ a,b,c maiúsculo e minúsculo } \\
\text { 3으 bastardo } \\
\text { 4으 bastardinho } \\
\text { 5을 cursivo }\end{array}$ \\
\hline 3a.Aritmética & $\begin{array}{l}\text { 10 numeração } \\
\text { 20 somar } \\
\text { 3o diminuir } \\
\text { 4o repartir } \\
\text { 60 frações } \\
\text { 70 complexos } \\
\text { 8o proporções }\end{array}$ \\
\hline 4ạ. Religião & $\begin{array}{l}\text { 10 orações } \\
\text { 20 catecismo } \\
\text { 3o explicações de doutrina }\end{array}$ \\
\hline
\end{tabular}

Fonte: Elaborado pelo autor (2014).

Considerando a figura 01, por exemplo, o aluno Pedro Matte, número 5 na lista de chamada, com 9 anos na ocasião da matrícula, não tinha nenhum conhecimento em nenhuma das 4 classes quando iniciou seus estudos em 1 o de dezembro de 1859. Mas, em março de 1862 encontrava-se no sexto período, provavelmente uma adaptação feita pelo professor, escrevia o bastardinho, estava realizando operações de diminuir e em religião já estudava o catecismo.

Em relação aos aspectos de Índole, Inteligência e Comportamento, os alunos eram avaliados por conceitos. Índole: Boa; Má. Inteligência: Pouca; Regular e Muita. Comportamento: Bom; Pouco e Deficiente. No mapa trimestral ainda registra-se o número de faltas dos alunos e há um campo para observações. Todos os alunos de Meyer apresentavam boa índole, no quesito inteligência a grande maioria é regular e oito alunos registram muita. O comportamento dos alunos é bom, com dois registros de alunos com pouco comportamento e dois com deficiente. Em relação ao maior número de faltas, o registro é do aluno Hadriano José de Oliveira, ausente 68 dias letivos no primeiro trimestre. 
A partir dos mapas de frequência trimestral analisados, observa-se que as turmas eram constituídas pela média de sessenta e seis alunos que frequentavam de 68 a 71 dias letivos em cada trimestre. Como referido anteriormente, um aspecto interessante é o registro da naturalidade dos alunos que consta a chegada de muitos alunos emigrados, que eram matriculados na aula deste professor Meyer, e permaneciam poucos dias, até que os pais se dirigissem para as localidades do interior do Vale dos Sinos. Em relação ao trabalho pedagógico desta Aula Pública constata-se que o professor valia-se do método intuitivo, bem como de cartilhas e materiais pedagógicos que foram reproduzidos pela Rotermund situada na cidade de São Leopoldo desde a segunda metade do século XIX.

Em síntese, a imigração germânica em Lomba Grande contribuiu para que o processo de institucionalização escolar se desenvolvesse neste lugar. Como argumenta Dreher (2000), uma das características culturais marcante das colônias alemães é a escola, instalada antes mesmo da igreja. Aspecto singular destes imigrantes, pois nas colônias dos poloneses e italianos como nos povoamentos dos lusos, constrói-se em primeiro lugar uma igreja, que domina sozinha durante muito tempo. Além disso, a presença dos Brummer e de imigrantes com instrução superior favoreceu para que uma importante relação de organização escolar fosse construída; bem como, garantiu a instrução dos filhos dos colonos que nas décadas seguintes ocupam, inclusive, funções políticas, liberais e autônomas.

\section{Considerações Finais}

A sorte dos Brummer, com a dispersão dos soldados em 1852, conduziu as mais diferentes práticas sociais desempenhadas na província, dentre elas o magistério. Dreher (2014) argumenta que nem todos obtiveram sucesso, pois alguns morreram, outros não conseguiram retornar para sua terra natal. O principal legado cultural destes imigrantes, talvez seja a divulgação da filosofia agnóstica, principalmente aspectos ligados às ciências naturais.

Amado (2002) argumenta que o relacionamento dos Brummer com os primeiros imigrantes não foi naturalmente tranquilo. Eram vistos como homens da cidade e intelectuais, cuja fala era talvez tão incompreensível quanto a língua portuguesa. $\mathrm{O}$ conhecimento da língua francesa favorecia que rapidamente aprendessem outras línguas contribuindo também para que ocupassem atividades liberais, como a imprensa jornalística, a escrita literária e o magistério. 
Em Lomba Grande, a escola assumiu, desde a segunda metade do século XIX, um papel indispensável para os imigrantes alemães, para disseminar o aprendizado da língua nacional. É possível que a implantação de Aulas Públicas e/ou de escolas subvencionadas ${ }^{14}$, em localidades que representaram isolamento das comunidades étnicas estrangeiras tenha operado com propósito de disciplinar a aprendizagem do português. Era importante que os filhos dos imigrantes conseguissem se comunicar na nova terra, dessa prática dependeria a sobrevivência e o sucesso esperado.

O aumento da oferta de escola, no final do século XíX, está associado a educação popular no Brasil que se tornou pauta política e nas duas primeiras décadas do século XX, em grande parte por causa da onda de nacionalismo gerada pela Primeira Guerra Mundial. Como se identifica neste estudo a subvenção escolar e a abertura de aulas públicas com professores efetivos endossam as diferentes maneiras que foram implantadas para desenvolver uma rede de ensino primário capaz de alfabetizar e instruir o povo o sentimento pátrio. A campanha pela divulgação da escola elementar que apelava ao sentimento nacionalista salientou a necessidade de se recuperar a imagem do Brasil no exterior: país onde havia mais analfabetos no mundo, além de cercear "o inimigo estrangeiro", fazendo chegar escola pública nas regiões rurais colonizadas por imigrantes alemães.

\section{REFERÊNCIAS}

AMADO, J. A revolta dos mucker: Rio Grande do Sul, 1868-1898. 2. ed. São Leopoldo: Editora Unisinos, 2002.

BACELLAR, C. Fontes documentais. Uso e mau uso dos arquivos. In: PINSKY, C. B. (Org.). Fontes históricas. São Paulo: Contexto, 2011, pp. 145-164.

BURKE, P. O que é história cultural? Tradução de Sérgio Góes de Paula. Rio de Janeiro: J. Zahar, 2005.

CELLARD, A. A análise documental. In: POUPART, J. et al. A pesquisa qualitativa: enfoques epistemológicos e metodológicos. Petrópolis, Vozes, 2008, pp. 295-315.

CHARTIER, R. À beira da falésia: a história entre incertezas e inquietude. Trad. Patrícia Chittoni Ramos. Porto Alegre: Ed. Universidade, 2002.

DREHER, M. N. Breve história do ensino privado gaúcho. São Leopoldo: Oikos, 2008.

. Notas para uma História da Educação protestante no Brasil. Estudos Leopoldenses. Série Educação, Unisinos, vol.4, no 6, janeiro/junho, 2000, p.133 - 150.

\footnotetext{
${ }^{14}$ Lendo os relatórios da intendência municipal de São Leopoldo e as petições para abertura de aulas no início do século XX, sugere-se que um dos requisitos estabelecidos pelo governo do Estado para abertas de tais aulas era o ensino da língua vernácula, ou seja, associava-se a subvenção, a escola e a escola ao ensino da língua portuguesa.
} 
. Protestantismo de imigração no Brasil: sua implantação no contexto liberal-modernizador e as conseqüências desse projeto. In: DREHER, M. N. Imigrações e história da Igreja no Brasil. Aparecida: Editora Santuário, 1993. pp. 109-131.

Apontamentos para a história da comunidade evangélica de Campo Bom. In: SPERB, A. T. (Org.). Sal da Terra: 160 anos da Comunidade e Escola Evangélica de Campo Bom. Canoas: Gráfica Editora La Salle, 1992. pp. 13-14.

Wilhem Rotermund. Seu Tempo - suas obras. São Leopoldo: Oikos, 2014.

FARIA FILHO, L. M. de. Instrução elementar no século XIX. In: LOPES, E. M. T.; FARIA FILHO, L. M. de; VEIGA, C. G. (Org.). 500 anos de educação no Brasil. 4. ed. Belo Horizonte: Autêntica, 2010. pp. 135150.

FERNANDES, D. R. Costa da Serra no Império. In: FERNANDES, E.; NEUMANN, R. M.; WEBER, R. Imigração: diálogos e novas abordagens. São Leopoldo: Oikos, 2012, pp.38-47.

FLECK, L. A saga do vale: história da imigração alemã no Vale do Rio dos Sinos., Sapiranga: [s.n.], 2001. 2 v.

FRAGO, A. V. Os cadernos escolares como fonte histórica: aspectos metodológicos e historiográficos. In: MIGNOT, A. C. V. (Org.). Cadernos à vista: escola, memória e cultura escrita. Rio de Janeiro: EdUERJ, 2008. pp. 15-34.

GERTZ, R. Conflitos intraétnicos em uma região de colonização alemã: o processo de emancipação de Novo Hamburgo. In: FERNANDES, E.; NEUMANN, R. M.; WEBER, R. Imigração: diálogos e novas abordagens. São Leopoldo: Oikos, 2012, pp. 48-60.

GOMES, D. A. Rastros que não se apagam: vida - história e árvore genealógica de Adriano Antônio Gomes. [S.I: s.n., 2000].

GRÜTZMANN, I.; DREHER, M. N.; FELDENS, J. A. Imigração alemã no Rio Grande do Sul. São Leopoldo: Oikos, 2008.

JULIÁ, D. A cultura escolar como objeto histórico. Tradução de Gizele de Souza. Revista brasileira de História da educação, Campinas, SP: Autores Associados, n.1, pp. 9-44, jan./jun. 2001.

KERBER, A.; SCHEMES, C.; PRODANOV, C. C. Memórias das práticas educativas durante o primeiro governo Vargas na cidade de Novo Hamburgo - RS. Revista brasileira de história da educação, Campinas, SP, v. 12, n. 2, pp. 139-170, maio/ago. 2012.

KREUTZ, L. Escolas comunitárias de imigrantes no Brasil: instâncias de coordenação e estruturas de apoio. Revista brasileira de educação, Rio de Janeiro, n. 15, pp.159 - 177, set.-dez. 2000.

. A Escola Teuto-Brasileira Católica e a Nacionalização do Ensino. In: Nacionalização e imigração alemã. MÜLLER, T. (Org.). Nacionalização e imigração alemã. São Leopoldo: Ed. UNISINOS, 1994. pp. 27- 64.

. Escolas étnicas na história da educação brasileira: a contribuição dos imigrantes. In:

STEPHANOU, M.; BASTOS, M. H. C. (Org.). História e memórias da educação no Brasil. Petrópolis, RJ: Vozes, 2005. v. 2: século XIX, pp. 150-165. 
KREUTZ, L. Igreja Católica e processo escolar entre os imigrantes alemães católicos no Rio Grande do Sul. In: DREHER, M. N. (Org.). 500 anos de Brasil e Igreja na América Meridional. Porto Alegre: EST, 2002. pp. 472-480.

MARQUES, L. A. S. Memórias de um professor: a instigante história de vida do professor Frederico Michaelsen - De imigrante contratado como soldado mercenário na Guerra contra Rosas em 1851 (Argentina) a professor primário em Colônia alemã do Rio Grande do Sul. História da Educação, ASPHE/FAE/UFPel, Pelotas, v. 14, n. 30, pp. 181-205, jan./abr. 2010. Acesso em: 10 de fev. 2014. Disponível em: <HTTP//FAE.ufpel.edu.br/asphe>

MÜLLER, T. L. Colônia alemã, 160 anos de história. Porto Alegre, Escola Superior de Teologia São Lourenço de Brindes; Caxias do Sul, Editora da Universidade de Caxias do Sul, 1984.

OLIVEIRA, L. M. L. Memórias e experiências: desafios da investigação histórica. In: FENELON, Déa Ribeiro et al. Muitas memórias, outras histórias. São Paulo: Olho D'água, 2004.

PESAVENTO, S. J. História \& História Cultural. 2a ed. Belo Horizonte: Autêntica, 2004.

RAMBO, A. B. A Igreja dos imigrantes. In: DREHER, M. N. (Org.). 500 anos de Brasil e Igreja na América meridional. Porto Alegre: EST, 2002. pp. 57-73.

A Escola comunitária teuto-brasileira católica. São Leopoldo: Unisinos, 1994.

SANTANA, Nara Maria Carlos de. Colonização alemã no Brasil: uma história de identidade, assimilação e conflito, Dimenões, v. 25, 2010, pp. 235-248.

SCHELBAUER, A. R. As bases da construção do sistema educacional durante o Segundo Reinado (1850-1889). In: ROSSI, E. R.; RODRIGUES, E.; NEVES, F. M. (Org.). Fundamentos históricos da educação no Brasil. 2. ed. revista e ampliada. Maringá: Eduem, 2009. p. 77-88.

SCHNEIDER, R. P. A instrução pública no Rio Grande do Sul. 1770-1889. Porto Alegre: Ed. Universidade/UFRGS/EST Edições, 1993.

SOUZA, J. E. de. As Escolas Isoladas: práticas e culturas escolares no meio rural de Lomba Grande - RS (1940 a 1952). 2015. 292 f. Tese (Doutorado em Educação) - Unisinos, São Leopoldo, RS, 2015.

O Pastor Klingelhoeffer e a revolução farroupilha: Uma contribuição ao cinquentenário da emancipação política de Campo Bom. São Leopoldo: Oikos, 2009.

Um personagem da memória Campo-bonense? O emblemático Pastor Klingelhoeffer, soldado Farroupilha. Oficina do Historiador, Porto Alegre/EDIPUCRS, v. 3, n. 2, p. 31-44, ago. 2011. Disponível em:

<http://revistaseletronicas.pucrs.br/ojs/index.php/oficinadohistoriador/article/view/9033/6449>. Acesso em: 8 fev. 2013.

Escola Comunitária e o Colégio Sinodal Tiradentes: 185 anos de história e educação

em Campo Bom. Jornal O Fato, Sapiranga, p. 2 - 2, 15 mar. 2013.

STEPHANOU, M.; BASTOS, M. H. C. História, memória e história da educação. In: STEPHANOU, M.; BASTOS, M. H. C. História e memórias da educação no Brasil. Petrópolis, RJ: Vozes, 2005. v. 3: século $X X$, p. 416-430. 
THUM, Carmo. Educação, história e memória: silêncios e reinvenções pomeranas na Serra dos Tapes. 2009. 383 f. Tese (Doutorado em Educação) -- Programa de Pós-Graduação em Educação, Universidade do Vale do Rio dos Sinos, São Leopoldo, RS, 2009.

TESCHE, Leomar. O séc. XIX os Brummer e a introdução da Turnen/Ginástica no Brasil. In: ANAIS... XXVII SIMPÓSIO NACIONAL DE HISTÓRIA. Conhecimento histórico e diálogo social. Natal, R.N, 22 a 26 de jul. de 2013, pp. 1-16.

\section{FONTES}

Documentos pesquisados no ACESPLG - Acervo da Comunidade Evangélica São Paulo de Lomba Grande

SÃO LEOPOLDO. Comunidade Evangélica-Luterana De Lomba Grande. Aula da Comunidade Evangélica (1934 a 1939). [Livro de frequência]. São Leopoldo-RS, Lomba Grande, 1934.

SÃO LEOPOLDO. Comunidade Evangélica-Luterana De Lomba Grande. Frequência dos alunos da Aula Evangélica Alemã da comunidade da Lomba Grande. [Livro de frequência]. São Leopoldo-RS, Lomba Grande, [1927?].

Documentos pesquisados no AIHGRS - Arquivo do Instituto Histórico e Geográfico do Rio Grande do Sul

ALMANACK Escolar do Rio Grande do Sul. Diretoria Geral da Instrucção Pública. Edição Official. Livraria Selbach de J. R. da Fonseca \& Cia. Porto Alegre, [1934?].

Documentos pesquisados no AHRS - Arquivo Histórico do Rio Grande do Sul

MEYER, Henrique. Título de nomeação [livro de apostillas 1880] folha manuscrita e sem numeração. Última assinatura é datada em Porto Alegre, 28 de abril de 1880. Assinado por Fernando Abbott Diretor Geral da Instrução Pública]. Localização: AHRS. Fundo: Instrução Primária.

[Petição] remetida ao Excelentíssimo Senhor Presidente da Província. Rio Grande do Sul. São Leopoldo, RS, Lomba Grande, 7 mar. 1881. (19 folhas). Fundo: Instrução Primária. Maço 17. Caixa 8.

SÃO LEOPOLDO. [copia de Ofício 69a] petição de reabertura de Aula Pública em Lomba Grande. São Leopoldo, RS, 7 nov. 1859. Fundo: Instrução Pública. Lomba Grande. Maço 2. Caixa 3. AHRS.

LIVRO DE REGISTROS DA RELAÇÃO DAS CADEIRAS DE 1ㅇ E 2 GRAU DA INSTRUÇÃO PRIMÁRIA. De 1820 a 1880. Livros: I- 65; I - 66; I- 68; I-82; I- 135; I- 136. Diretoria da Instrução Pública. Fundo: Instrução Primária. AHRS.

Arquivo do Museu Histórico Visconde de São Leopoldo-AMHVSL

MEYER, Henrique. [anexo 4: Especificação dos alunos dados prontos nos anos de 1860 a 1876]. Aula Pública do sexo masculino. Lomba Grande, 1ㅇ distrito da cidade de São Leopoldo.Correspondência encaminhada à Francisco Coelho da Silva. São Leopoldo, 30 de agosto de 1876. Fundo: Escolas. Caixa 2. Arquivo do Museu Histórico Visconde de São Leopoldo. São Leopoldo, R.S. 